Research paper

\title{
Anxiety and anhedonia in depression: Associations with neuroticism and cognitive control ${ }^{\text {is }}$
}

\author{
Allen Liao ${ }^{\mathrm{i}}$, Robrina Walker ${ }^{\mathrm{a}, 1}$, Thomas J. Carmody ${ }^{\mathrm{a}}$, Crystal Cooper ${ }^{\mathrm{a}}$, Meredith A. Shaw ${ }^{\mathrm{b}}$, \\ Bruce D. Grannemann ${ }^{\mathrm{a}}$, Phil Adams ${ }^{\mathrm{c}}$, Gerard E. Bruder ${ }^{\mathrm{c}}$, Melvin G. McInnis ${ }^{\mathrm{d}, 1}$, \\ Christian A. Webb ${ }^{\mathrm{e}}$, Daniel G. Dillon ${ }^{\mathrm{e}, 1}$, Diego A. Pizzagalli ${ }^{\mathrm{e}, 1}$, Mary L. Phillips ${ }^{\mathrm{f}}$, Benji T. Kurian ${ }^{\mathrm{a}}$, \\ Maurizio Fava $^{\mathrm{e}, 1}$, Ramin V. Parsey ${ }^{\mathrm{g}}$, Patrick J. McGrath ${ }^{\mathrm{c}, 1}$, Myrna M. Weissman ${ }^{\mathrm{h}, 1}$, \\ Madhukar H. Trivedi ${ }^{a, *, 1}$
}

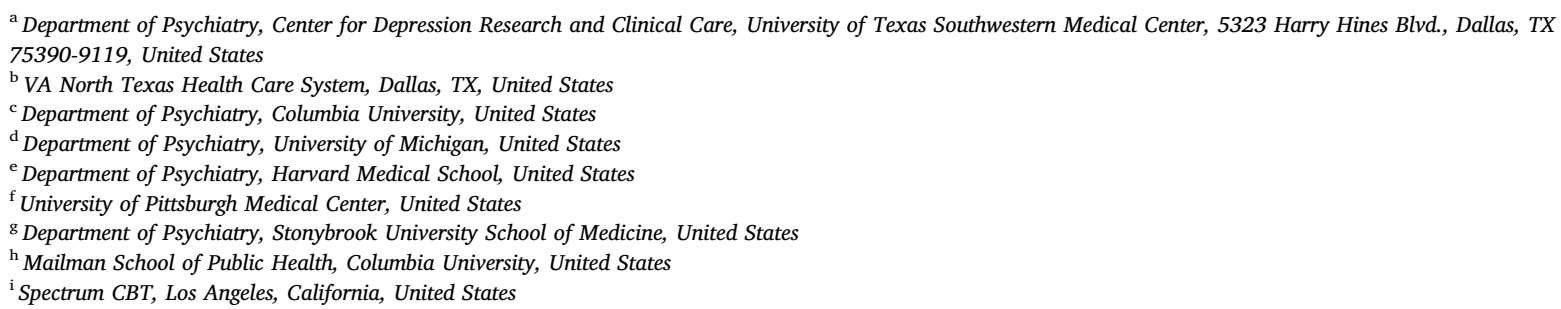

\section{A R T I C L E I N F O}

\section{Keywords:}

Anxiety

Anhedonia

Depression

Neuroticism

Cognitive control

\begin{abstract}
A B S T R A C T
Background: Despite the fact that higher levels of anxiety and anhedonia in Major Depressive Disorder (MDD) are linked to poorer treatment outcomes, mechanisms contributing to these clinical presentations remain unclear. Neuroticism, impaired cognitive control, and blunted reward learning may be critical processes involved in MDD and may help to explain symptoms of anxiety and anhedonia.

Methods: Using baseline data from patients with early-onset $\operatorname{MDD}(N=296)$ in the Establishing Moderators and Biosignatures of Antidepressant Response in Clinical Care (EMBARC) trial, we conducted a path analysis to model relationships between neuroticism, cognitive control, and reward learning to levels of anxiety and anhedonia.

Results: Neuroticism was positively associated with both anhedonia (standardized coefficient $=0.26, p<.001$ ) and anxiety (standardized coefficient $=0.40, p<.001$ ). Cognitive control was negatively associated with anxiety (standardized coefficient $=-0.18, p<.05$ ). Reward learning was not significantly associated with either anxiety or anhedonia.

Limitations: Extraneous variables not included in the model may have even more influence in explaining symptoms of anxiety and anhedonia. Restricted range in these variables may have attenuated some of the hypothesized relationships. Most important, because this was a cross-sectional analysis in a currently depressed sample, we cannot draw any causal conclusions without experimental and longitudinal data.

Conclusions: These cross-sectional findings suggest that neuroticism may contribute to anxiety and anhedonia in patients with early onset and either chronic or recurrent MDD, while enhanced cognitive control may protect against anxiety.
\end{abstract}

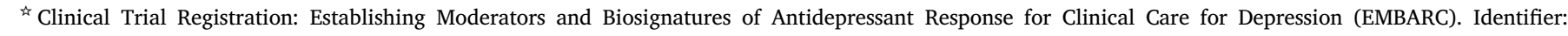
NCT01407094. URL: http://clinicaltrials.gov/show/NCT01407094.

* Corresponding author.

E-mail address: Madhukar.Trivedi@UTSouthwestern.edu (M.H. Trivedi).

${ }^{1}$ Drs. Walker, McInnis, Dillon, Pizzagalli, Fava, McGrath, Weissman, and Trivedi all have conflicts to reports. All other authors report none. The full account can be found at manuscript's end. 


\section{Introduction}

The clinical presentation of major depressive disorder (MDD) varies from person to person, and the lack of attention to this heterogeneity has stifled treatment advances. Symptom presentations associated with high anxiety (e.g., worry, restlessness) and anhedonia (e.g., empty mood, loss of pleasure) are especially impairing and linked to worse treatment outcomes such as lower likelihood of depression remission (Fava et al., 2008) and longer time to remission (McMakin et al., 2012). To improve treatment precision and clinical outcomes, we must identify the mechanisms underlying the varied symptoms associated with depression. The overall aim of the current study was to simultaneously evaluate how neuroticism, cognitive control, and reward learning may be potential underlying mechanisms of anxiety and anhedonia symptoms. The primary aim was to determine if the relationship between neuroticism and anxiety is moderated by cognitive control, such that individuals with greater cognitive control have fewer anxiety symptoms. We evaluated our hypotheses in a sample of patients with MDD from the Establishing Moderators and Biosignatures of Antidepressant Response in Clinical Care (EMBARC) study (Trivedi et al., 2016; Webb et al., 2016).

Neuroticism (the propensity to experience negative emotions), cognitive control (the regulation of thoughts and actions in the service of goal-directed behavior), and reward learning (the modulation of behavior in response to reward) demonstrate strong, independent associations with MDD (see Goldstein and Klein, 2014 for review). Each has also been examined in large longitudinal studies: neuroticism prospectively predicted the first onset of unipolar mood disorders and anxiety disorders (Zinbarg et al., 2016), cognitive control deficits in childhood were associated with subsequent increases in depression and anxiety symptoms (Kertz et al., 2016), and reduced reward learning increased the likelihood of poor response to treatment in MDD (Vrieze et al., 2013). However, we are not aware of any studies that have examined these constructs in combination with each other or in relation to the specific, distinct symptom presentations of anxiety and anhedonia in MDD.

In the current study, we developed and tested an explanatory model elucidating cross-sectional relationships between anxiety and anhedonia in MDD and the constructs of neuroticism, cognitive control, and reward learning (see Fig. 1 diagram of all hypothesized relationships). We hypothesized neuroticism, characterized by a propensity toward negatively valenced self-referential thinking such as worry and rumination (Muris et al., 2005; Segerstrom et al., 2000), will be associated with higher levels of anxiety and anhedonia. The impaired disengagement model of rumination (Koster et al., 2011) posits that impaired attentional control is associated with sustained rumination, leading to negative affect. Recent findings (Hsu et al., 2015; Vasey et al., 2013) indicate greater cognitive control may help individuals cope with worry and rumination, which may be particularly important in individuals high in neuroticism exhibiting greater mind-wandering and poorer attentional control (Robison et al., 2016). Thus, we hypothesized cognitive control will moderate the relationship between neuroticism and anxiety. We further hypothesized that greater reward learning ability may contribute to increased reward-seeking behavior and experience of positive emotions. Thus, we expected reward learning to be associated with lower anhedonia.

\section{Method}

\subsection{Study overview and participants}

We analyzed baseline data from the Establishing Moderators and Biosignatures of Antidepressant Response in Clinical Care (EMBARC; Trivedi et al., 2016) study, a four-site, placebo-controlled trial of antidepressant treatment in outpatients with MDD. Eligible participants, aged 18-65, had a current MDD episode per the Structured Clinical
Interview for DSM-IV Axis I Disorders, scored $\geq 14$ on the Quick Inventory of Depression Symptomatology and were antidepressant-free for $>3$ weeks before assessments. Recruitment was restricted to participants with early onset (before age 30 ) and chronic (episode duration $>2$ years) or recurrent MDD ( $2+$ recurrences) were enrolled. Exclusion criteria included: antidepressant treatment failure in current episode, history of inadequate response to sertraline or bupropion, currently receiving depression-specific psychotherapy, current medications with potential to interfere with study medications, history of psychosis or bipolar disorder, DSM-IV past 6 month substance dependence (excluding nicotine) or past 2 month abuse, other unstable psychiatric or medical conditions requiring hospitalization or contraindicating study medications, pregnant or breastfeeding, clinically significant laboratory abnormalities, or history of epilepsy or anticonvulsant use.

Participants $(N=296)$ were recruited from the community, screened, and provided informed consent following IRB approved procedures. Trained and qualified assessors administered clinical and behavioral measures. Participants completed clinical, self-report, behavioral, and physiological baseline assessments.

\subsection{Measures}

\subsubsection{Anxiety}

The 20 item State Anxiety scale of the State-Trait Anxiety Inventory (STAI) (Spielberger, 2010) assessed anxiety (e.g., "I feel- tense; nervous; worried") on a 4-point scale ("not at all" to "very much so"). Higher scores (20-80) indicate greater anxiety, with scores $>52$ being clinically significant (Balsamo et al., 2013; Stauder and Kovacs, 2003). STAI State Anxiety strongly correlates with anxiety severity in major depression $(r=0.72)$; there are no significant differences between state and trait anxiety scores in individuals with anxiety and depressive disorders (Kennedy et al., 2001). In our analysis, state anxiety scores are a proxy for anxiety symptoms. In a reliability generalization study of the STAI, the State Anxiety score demonstrated strong internal consistency $(\alpha=0.91)$, satisfactory test-retest reliability $(r=0.70)$ (Barnes et al., 2002), and is a valid measure of anxiety in clinical populations (Oei et al., 1990). In our sample, internal consistency for the STAI State Anxiety score was excellent $(\alpha=0.93)$.

\subsubsection{Anhedonia}

The 14-item Snaith-Hamilton Pleasure Scale (SHAPS; Snaith et al., 1995) measured anhedonia. Items assess hedonic experience in "the last few days" for naturally pleasurable activities, including social interaction, sensory experience, and food/drink (e.g., "I would find pleasure in my hobbies and pastimes"). Items have four responses, with "Agree" or "Strongly Agree" equalling 0, and "Disagree" or "Strongly Disagree" equalling 1 . Scores range from 0 to 14 , with higher scores indicating higher state anhedonia levels, and a score $>2$ signifying abnormal hedonic tone. In a depressed outpatient sample, the SHAPS had high internal consistency $(\alpha=0.91)$ and a unidimensional structure with good convergent and discriminant validity as compared to multiple clinician-rated depression measures (Nakonezny et al., 2010). In our sample, internal consistency was satisfactory ( $\alpha=0.78$ ).

\subsubsection{Neuroticism}

The NEO Five-Factor Inventory (NEO-FFI-3) 60-item self-report measure assesses the "Big Five" personality traits (McCrae and Costa, 2010). The Neuroticism factor (12 items) assesses emotional response tendencies (e.g., "When I'm under a great deal of stress, sometimes I feel like I'm going to pieces."), rated on a 5-point scale ("Strongly Disagree" to "Strongly Agree"), with total scores of 0-48. In adults, internal consistency for Neuroticism is good $(\alpha=0.86)$ and factor structure is well replicated (McCrae and Costa, 2007). In our sample, the NEO-FFI-3 Neuroticism score exhibited satisfactory internal consistency ( $\alpha=0.74)$. 


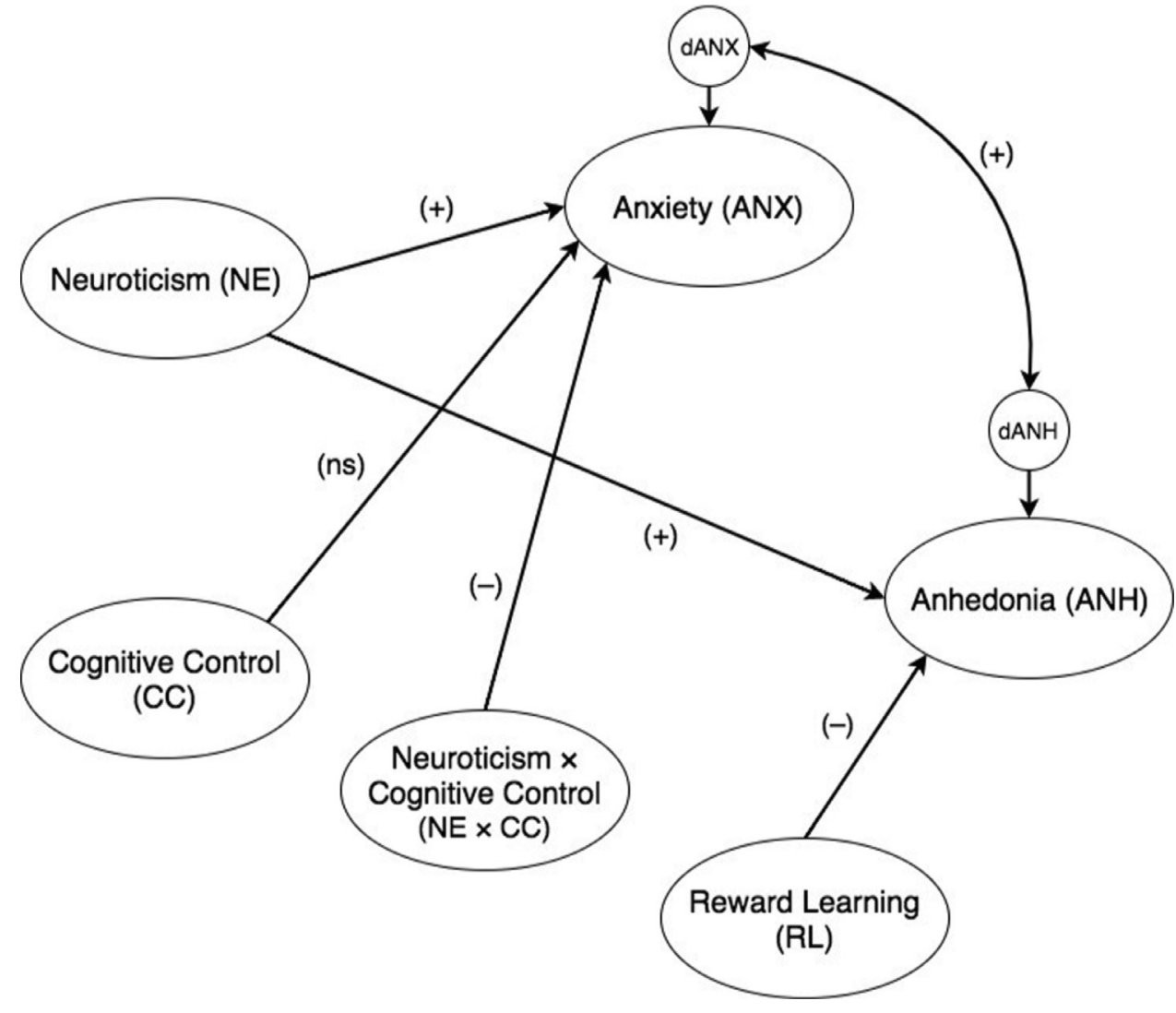

Fig. 1. Hypothesized full model. The $(+)$ or $(-)$ signs indicate the hypothesized direction of the path coefficient; each is hypothesized to reach significance at $p<.05$. (ns) indicates a nonsignificant effect. The curved doubleheaded arrow indicates correlated disturbances. All exogenous variables were allowed to freely correlate, and are not depicted in this figure.

\subsubsection{Cognitive control}

A version of the Eriksen Flanker Task (Eriksen and Eriksen, 1974; Holmes et al., 2010) assessed cognitive control (see Supplementary Material for details). Participants were seated at a computer with both hands on the keyboard, presented with a row of arrows on-screen, and responded as quickly and accurately as possible (via keyboard button press) with either left or right index finger, corresponding to the direction of the center arrow (left or right). The center arrow had adjacent flanking arrows (two on each side), which either pointed in the same direction (congruent trials) or in the opposite direction (incongruent trials) of the center arrow. Participants completed 5 blocks of 70 trials in each block (46 congruent trials, 24 incongruent trials). Accuracy and reaction time (RT) were recorded, and interference effects were defined as longer RT and poorer accuracy on incongruent as compared to congruent trials.

We use the RT interference effect as our primary measure, as RT is more sensitive to cognitive control processes (Prinzmetal et al., 2005). Greater interference effect scores reflect greater deficits in cognitive control, computed as the difference between the mean RT on incongruent trials and the mean RT on congruent trials, across all five blocks. The RT interference effect variable was reverse scored such that higher scores represent greater levels of cognitive control. Interference effects have been used as a behavioral indicator of cognitive control, reflecting conflict monitoring in the anterior cingulate cortex (Botvinick et al., 1999). The Flanker task also showed good test-retest reliability (ICC $=0.80)$ in adults, and convergent and divergent validity with other cognitive measures (Weintraub et al., 2013). In our sample, testretest reliability over 1 week, utilizing scores for clinically stable individuals (i.e., 61 placebo non-responders), demonstrated acceptable reliability $(r=0.59)$.

\subsubsection{Reward learning}

The Probabilistic Reward Task (PRT) (Pizzagalli et al., 2005) assessed reward learning. This paradigm utilizes signal detection theory and differential reinforcement schedules consisting of financial reward, resulting in a response bias over time (Pizzagalli et al., 2008; also see Supplementary Material). Participants were seated at a computer and informed that the purpose of the game was to maximize monetary earnings, but not every correct response is rewarded. Participants were asked to determine (via keyboard button press) which of two briefly presented $(100 \mathrm{~ms})$ stimuli was presented on the screen: a short or long mouth, superimposed on a cartoon face. Participants completed 2 blocks of 100 trials each. The reinforcement ratio was asymmetric; correctly identifying the short mouth ("rich" stimulus) was rewarded ("Correct!! You won 5 cents") three times more frequently than the long mouth ("lean" stimulus). Participants were paid a predetermined fixed amount after task completion. A participant's tendency to identify the more frequently rewarded ("rich") stimulus is captured by response bias (logb) scores, computed as follows (Pizzagalli et al., 2008):

$$
\begin{gathered}
\log b=0.5^{*} \log \left\{\left[\left(\text { Rich }_{\text {Correct }}+0.5\right)^{*}\left(\operatorname{Lean}_{\text {Incorrect }}+0.5\right)\right] /\right. \\
\left.\left[\left(\text { Rich }_{\text {Incorrect }}+0.5\right)^{*}\left(\operatorname{Lean}_{\text {Correct }}+0.5\right)\right]\right\}
\end{gathered}
$$

Our variable of interest is the change in response bias (RB) scores from the first to the second block of trials $\left(R B_{\text {Block } 2}-R B_{\text {Block 1 }}\right)$, reflecting behavioral adjustments in response to selective reward feedback, i.e., reward learning. Evidence of the validity of the PRT response bias as a behavioral indicator for reward learning has appeared in healthy controls and clinical populations (Huys et al., 2013). Onemonth test-retest reliability of response bias scores has proven adequate $(r=0.57)$ in a sample of undergraduate students (Pizzagalli et al., 2005). In the current sample, test-retest reliability over 1 week for clinically stable individuals (i.e., 57 placebo non-responders) was unexpectedly poor $(r=0.11)$.

\subsection{Analytical plan}

Prior to analysis, data were examined and assumptions of structural equation modeling (SEM) analysis, which was used to test the 
hypothesized relationships and assess model fit were met (i.e., assumptions of linearity, homoscedasticity, multivariate normality, multicollinearity, and singularity). Model-based corrections for measurement error were applied using a latent variable structural equation model to conduct path analysis (Cole and Preacher, 2014). Each observed variable serves as a single indicator for a latent (error-adjusted) variable representing that construct. For each observed variable, the factor loading is set to 1.0, and error variance is fixed to a value based on a reliability estimate $\left(\rho_{\mathrm{xx}}\right)$ of that measure $\left[\left(1-\rho_{x x}\right) \times\right.$ variance] calculated from the current sample (see Measures). Each observed variable is represented by a single-indicator latent construct (in parentheses), thus accounting for measurement error in the model. Endogenous (i.e., dependent) variables include STAI State Anxiety score (ANX) and SHAPS total score. Exogenous (i.e., independent) variables include NEO-FFI-3 Neuroticism factor score (NE), interference effect on $\mathrm{RT}$ in the Flanker task (CC), and change-in-response bias across blocks in the PRT (RL). A mean-centered interaction term, the Neuroticism score $\times$ Flanker RT interference effect $(\mathrm{NE} \times \mathrm{CC})$ was computed as a fourth exogenous variable. This interaction term was computed in order to test for moderation in the model.

SPSS AMOS (version 24.0) was used, building models in an iterative procedure based on maximum likelihood estimation, using full information maximum likelihood to handle missing data. The hypothesized model (see Fig. 1) was estimated first. Post-hoc model modifications were made using empirical results. Paths in the structural model were evaluated for statistical significance, and non-significant paths were trimmed from the model one at a time, re-estimating model fit after each path was trimmed. The relative fit of each model was evaluated using the Akaike Information Criterion (AIC), where smaller values indicate a more parsimonious model (Burnham et al., 2011). This resulted in fitting three models in total. The overall model fit was assessed with model fit indices of $\chi^{2}, \chi^{2} / \mathrm{df}$, CFI, RMSEA, PCFI, and AIC, all chosen based on current recommendations (Hooper et al., 2008; Hu and Bentler, 1999; Kline, 2015) suggesting these indices are least sensitive to sample size and model misspecification (see Supplementary Material for details).

\section{Results}

In this sample of depressed outpatients ( $N=296$; see Table 1$), 34 \%$ reported clinically significant anxiety (STAI-S $>52$ ) and $77 \%$ exhibited anhedonia (SHAPS $>2$ ), with $31 \%$ meeting the cutoff for both clinically significant anxiety and anhedonia. The correlation matrix with all observed variables in the model is summarized in Table 2.

The estimated hypothesized full model is depicted in Fig. 2, with model fit indices indicating a good fit, $\chi^{2}(3 \mathrm{df}, N=296)=3.41$, $p=.33, \chi^{2} / d f=1.14, \quad$ CFI $=0.993, \quad$ RMSEA $=0.022, \quad$ AIC $=51.41$. However, the model lacked parsimony, PCFI $=0.142$, and two paths were nonsignificant: reward learning to anhedonia (unstandardized coefficient $=1.500$, standardized coefficient $=0.035, p=.86$ ) and the path between the neuroticism $\times$ cognitive control interaction term and anxiety (unstandardized coefficient $=0.009$, standardized coefficient $=0.089, p=.24$ ). Post-hoc model modifications were then performed as described above, comparing AIC values to determine best model fit. The path between reward learning and anhedonia was deleted first and the model was then re-estimated. The trimmed model also fit the data well, $\chi^{2}(2 \mathrm{df}, N=296)=2.41, p=.30, \chi^{2} / \mathrm{df}=1.21$, $\mathrm{CFI}=0.993$, RMSEA $=0.027$, PCFI $=0.132$, AIC $=38.41$. One additional model was estimated by trimming the one remaining nonsignificant path between neuroticism $\times$ cognitive control and anxiety. This fully trimmed final model (see Fig. 3) also fit the data well, $\chi^{2}(1 \mathrm{df}$, $N=296)=0.35, \quad p=.55, \quad \chi^{2} / d f=0.35, \quad$ CFI $=1.000$, RMSEA $=0.000$, PCFI $=0.100$, AIC $=26.35$. The only exception to good model fit is the poor parsimony fit (PCFI). Comparing AIC values, the fully trimmed model has the smallest AIC value, with the difference in AIC between the models being $>10$, indicating the best fit
Table 1

Demographic and clinical characteristics $(N=296)$.

\begin{tabular}{|c|c|}
\hline & $\mathrm{M}(\mathrm{SD})$ or $n(\%)^{\mathrm{a}}$ \\
\hline Age, years & $37.1(13.3)$ \\
\hline Female & $194(66 \%)$ \\
\hline \multicolumn{2}{|l|}{ Race/ethnicity ${ }^{\mathrm{b}}$} \\
\hline White, Non-Hispanic & $155(52 \%)$ \\
\hline Hispanic & $55(19 \%)$ \\
\hline African American & $58(20 \%)$ \\
\hline Asian & $21(7 \%)$ \\
\hline Other & $23(8 \%)$ \\
\hline \multicolumn{2}{|l|}{ Marital status $(n=293)$} \\
\hline Single & $175(60 \%)$ \\
\hline Married & $58(20 \%)$ \\
\hline Divorced/Separated/Widowed & $59(20 \%)$ \\
\hline \multicolumn{2}{|l|}{ Employment status $(n=292)$} \\
\hline Full time & $92(32 \%)$ \\
\hline Part-time & $70(24 \%)$ \\
\hline Not employed & $130(45 \%)$ \\
\hline \multicolumn{2}{|l|}{ Education level $(n=292)$} \\
\hline Completed higher education & $127(43 \%)$ \\
\hline Some higher education & $104(36 \%)$ \\
\hline No higher education (high school or less) & $61(21 \%)$ \\
\hline \multicolumn{2}{|l|}{ Monthly household income level $(n=240)$} \\
\hline$>\$ 2000$ & $107(45 \%)$ \\
\hline$\$ 1000-2000$ & $75(31 \%)$ \\
\hline$<\$ 1000$ (Below poverty) & $58(24 \%)$ \\
\hline \multicolumn{2}{|l|}{ Family history $(n=293)$, first degree relatives with: } \\
\hline Serious mental illness & $158(53 \%)$ \\
\hline Depressed mood $\geq 2$ weeks & $186(63 \%)$ \\
\hline Age of onset of first Major Depressive Episode (MDE), years & $16.3(5.8)$ \\
\hline Lifetime MDE Characterization & Chronic (episode duration > 2 years) \\
\hline \multicolumn{2}{|l|}{$215(73 \%)$} \\
\hline Recurrent (mainly well, with $2+$ distinct episodes) & $81(27 \%)$ \\
\hline \multicolumn{2}{|l|}{ MDE Characteristics } \\
\hline \multirow{2}{*}{\multicolumn{2}{|c|}{ Severity of Current $\mathrm{MDE}^{\mathrm{d}}$}} \\
\hline & \\
\hline Mild & $14(5 \%)$ \\
\hline Moderate & $194(66 \%)$ \\
\hline Severe & $87(29 \%)$ \\
\hline "With anxious distress" specifier in current MDE & $114(39 \%)$ \\
\hline \multicolumn{2}{|l|}{ Severity of "anxious distress" $(n=114)^{\mathrm{d}}$} \\
\hline Mild & $30(26 \%)$ \\
\hline Moderate & $46(40 \%)$ \\
\hline Moderate-severe to severe & $38(33 \%)$ \\
\hline
\end{tabular}

${ }^{\text {a }}$ Numbers (\%) may not add up to $N=296$ due to missing data. Percentages are based on non-missing data and may not add up to $100 \%$ due to rounding error.

b Percentages sum to greater than $100 \%$ because participants reporting Hispanic ethnicity may be of any race and are therefore counted under more than one category.

${ }^{c}$ Due to severely positive skewed distribution, median (IQR) is reported instead of mean (SD). IQR, or interquartile range, is equal to the difference between the 75th and 25th percentiles.

d Severity levels were determined by clinical ratings according to the Structured Clinical Interview for DSM disorders (SCID).

\section{(Burnham et al., 2011).}

In the final model (Fig. 3), increased anxiety was associated with greater neuroticism (unstandardized coefficient $=0.798$, standardized coefficient $=0.400, p<.001$ ) and decreased cognitive control (unstandardized coefficient $=-0.108, \quad$ standardized coefficient $=-0.176, p<.05)$. Increased anhedonia was predicted by greater neuroticism (unstandardized coefficient $=0.140$, standardized coefficient $=0.256, p<.001$ ). Neuroticism was positively correlated with cognitive control $(r=0.312, p<.001)$, and the unexplained variance in anxiety correlated positively with the unexplained variance in anhedonia $(r=0.301, p<.001)$. Per the squared multiple correlations $\left(R^{2}\right)$, neuroticism and cognitive control accounted for $14.7 \%$ of the variance in anxiety, and neuroticism accounted for $6.5 \%$ of the variance in anhedonia. Because post hoc model modifications were 
Table 2

Correlations, means, and standard deviations of observed variables.

\begin{tabular}{|c|c|c|c|c|c|c|c|c|}
\hline Variable & 1 & 2 & 3 & 4 & 5 & 6 & $M$ & $S D$ \\
\hline 1. State-Trait Anxiety Inventory - State Anxiety (STAI-S) & - & & & & & & 48.22 & 11.54 \\
\hline 2. Snaith-Hamilton Pleasure Scale (SHAPS) & $0.31^{*}$ & - & & & & & 5.59 & 3.44 \\
\hline 3. NEO-Neuroticism (NEO-N) & $0.28^{*}$ & $0.20^{*}$ & - & & & & 34.86 & 6.48 \\
\hline 4. Flanker Task Reaction Time (Flanker RT) & -0.05 & 0.02 & $0.22 *$ & - & & & 64.19 & 22.54 \\
\hline 5. Probabilistic Reward Task change in Response Bias (PRT $\Delta \mathrm{RB}$ ) & -0.02 & 0.03 & 0.06 & -0.01 & - & & 0.02 & 0.21 \\
\hline 6. NEO-N × Flanker RT & 0.04 & -0.09 & -0.21 & 0.04 & 0.04 & - & 32.18 & 146.02 \\
\hline
\end{tabular}

Pearson correlation coefficient was calculated for each pair of variables for which data was available (cases excluded pairwise)

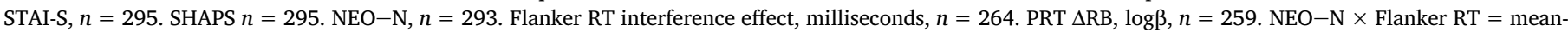
centered interaction term (product of mean-centered NEO-N and mean-centered Flanker RT), $n=262$.

* $p<.01$.

performed, a correlation was calculated between the parameter estimates from the hypothesized full model and the parameter estimates from the final model, $r(11)=1.000, p<.001$, indicating parameter estimates did not change significantly despite model modification, lending increased confidence to the generalizability of results.

\section{Discussion}

In our racially/ethnically and socioeconomically diverse sample of patients with moderate-to-severe depression severity and high levels of anxiety and anhedonia, we found neuroticism was positively associated with anxiety and anhedonia while cognitive control was independently and negatively associated with anxiety but not anhedonia. Contrary to hypotheses, cognitive control did not moderate the association between neuroticism and anxiety, and there was no significant association between reward learning and anhedonia. Our finding of neuroticism being associated with clinically significant anxiety replicates others' anxiety (e.g., Jylhä and Isometsä, 2006; Schuurmans et al., 2005; Zinbarg et al., 2016) and anhedonia (Wetter and Hankin, 2009) findings. One possible mechanism by which neuroticism affects both anxiety and anhedonia may be through the effects of rumination and worry. In both nonclinical (Muris et al., 2005) and clinical (Roelofs et al., 2008) samples, rumination was found to mediate the link between neuroticism and symptoms of both depression and anxiety, as well as later depressive symptoms (Barnhofer and Chittka, 2010; Mezulis et al., 2011). As predicted by the impaired disengagement hypothesis (Koster et al., 2011), rumination increases focus on the self and decreases focus on the environment, and this reduced attention to naturally-occurring environmental contingencies may lead to clinical anhedonia over time. We did not find evidence for cognitive control moderating the association between neuroticism and anxiety as we hypothesized. Instead, our behavioral measure of cognitive control was independently associated with lower levels of anxiety (i.e., better cognitive control is associated with less anxiety), consistent with the impaired disengagement

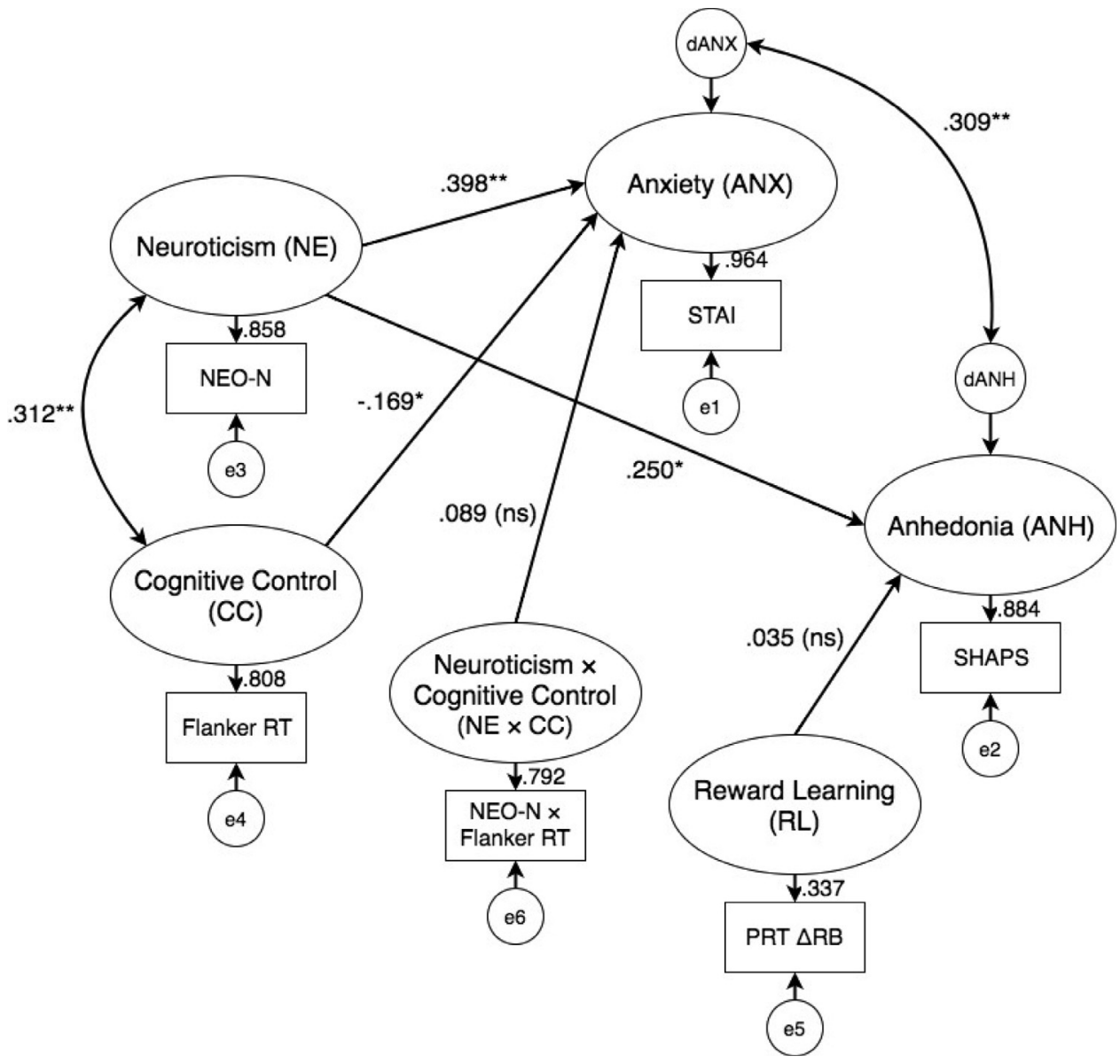

Fig. 2. Estimated full model. Rectangles represent observed variables, and ovals represent error-adjusted variables. Circles represent errors and disturbances. Single-headed arrows represent standardized direct effects. The curved double-headed arrows indicate correlations. Nonsignificant correlations between exogenous variables are not shown. ${ }^{*} p<.05$; $* * p<.001$; (ns) indicates nonsignificant effect. 


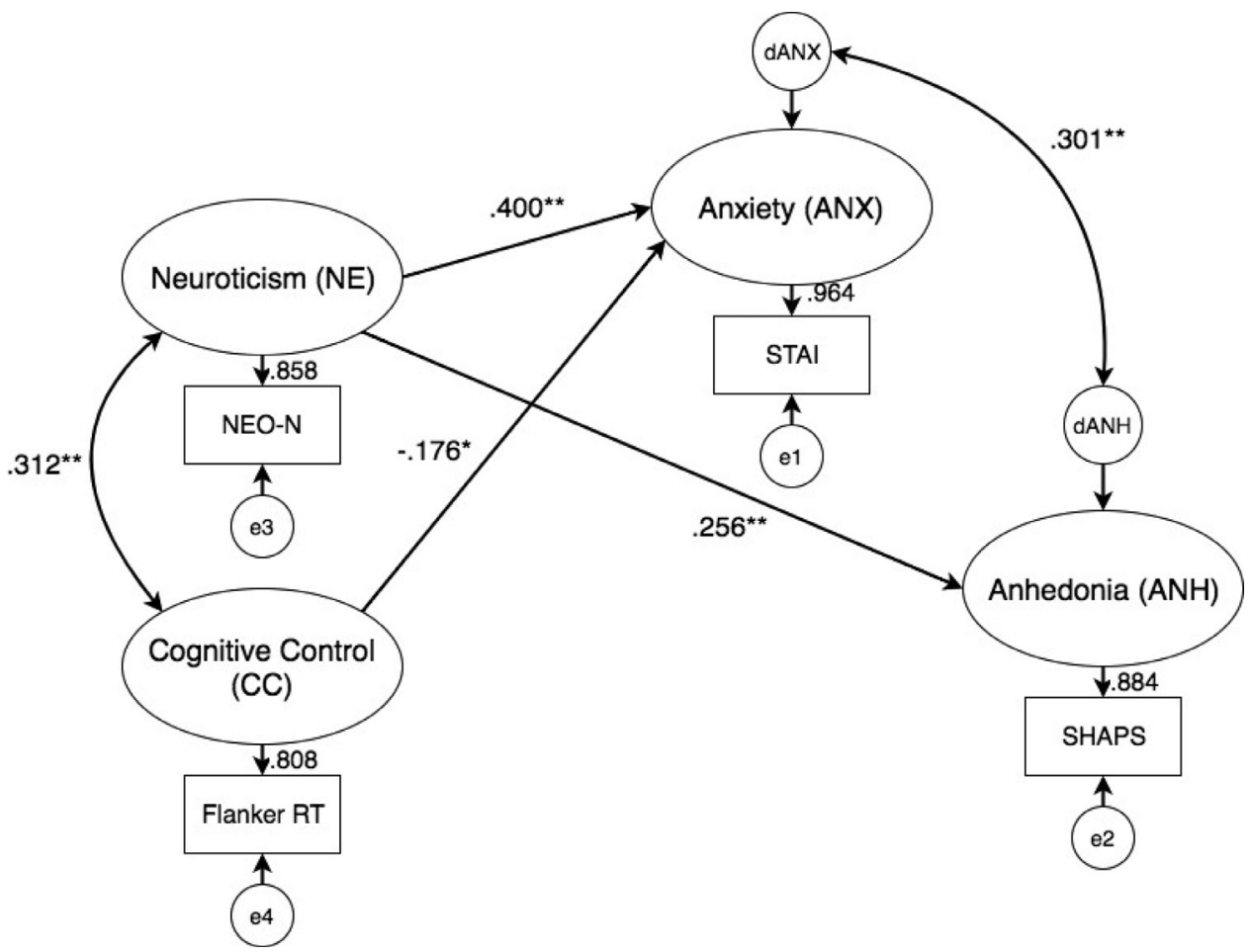

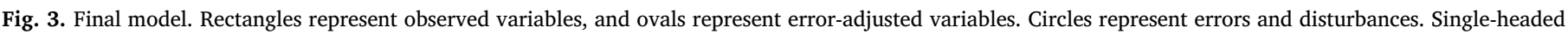
arrows represent standardized direct effects. The curved double-headed arrows indicate correlations. ${ }^{*} p<.05 ; * * p<.001$.

hypothesis. Our results are consistent with other studies that have analyzed behavioral measures of cognitive control (De Raedt and Koster, 2010; Paulus, 2015), but not studies that used self-report measures of cognitive control which have shown an interactive effect between neuroticism and cognitive control (Muris, 2006; Vasey et al., 2013). Thus, it appears the method of cognitive control measurement (behavioral or self-report) may account for the lack of consistency in the literature. This underscores the idea that behavioral and self-report measures of cognitive control are not interchangeable, as people may differ in their ability to self-report cognitive control (Necka et al., 2012). Behavioral measures may be more informative, for example, a recent longitudinal study using a behavioral measure of cognitive control showed that cognitive control deficits in preschool-aged children were independently associated with both increased depressive and anxiety symptoms over 7.5 years (Kertz et al., 2016).

Reward learning was not associated with anhedonia, contrary to previous studies (Liu et al., 2011; Liu et al., 2016; Pizzagalli et al., 2008; Vrieze et al., 2013). The test-retest reliability of the PRT was unexpectedly poor in this sample, which likely affected the ability to detect a relationship. One possible explanation for poor task reliability may be specific to this particular sample of individuals. Pizzagalli et al. (2005) reported that individuals with high depression severity failed to show any changes in response bias across blocks (i.e., reward learning), differing significantly from those with low depression severity. Because our sample was restricted to individuals with moderate to severe depression severity, low variability in reward learning in this sample may have led to the low observed reliability (i.e., if true score variability is low, reliability consequently will be low). Future studies examining samples with a wider range of depression severity scores may better elucidate a relationship between reward learning and anhedonia. It is also possible that other relevant factors may not have been captured in the hypothesized model. Reward sensitivity and learning rate may be separable components of reward learning that could be important to examine (Huys et al., 2013). Other factors (e.g., perceived control and stress) may also significantly affect the relationship between reward systems and anhedonia (Pizzagalli, 2014). In a recent review, Rizvi et al. (2016) concluded anhedonia is a multifaceted construct that includes different facets of hedonic function including desire, effort/motivation toward obtaining a reward, and anticipatory and consummatory pleasure. Because self-report measures like the SHAPS may only measure one facet of hedonic function, they may not always correlate with reward task performance. Multi-method assessment of anhedonia or examination of specific facets of anhedonia may help to clarify the relationship between reward learning and anhedonia.

One notable limitation of our study is that, due to the significant correlation between the unexplained variances of anxiety and anhedonia, extraneous variables not included in the model may have even more influence in explaining symptoms of anxiety and anhedonia. For example, outside factors (e.g., environmental stress) or psychological factors (e.g., repetitive negative thinking) may moderate variables not modeled in the current study. Because of the sample characteristics (high neuroticism, moderate to severe depression), restricted range in these variables may have attenuated some of the hypothesized relationships. Future studies would benefit from expanding the scope of the study to participants with greater range in neuroticism and depression symptom severity, including those with milder symptoms. Because these constructs cut across traditional diagnostic boundaries beyond MDD, further studies investigating the proposed model in a transdiagnostic sample may contribute to our understanding of psychopathology. Most important, because the current study was a crosssectional analysis of data from a currently depressed sample, we cannot draw any causal conclusions without experimental and longitudinal data. The current study is a secondary analysis of data from a trial not originally designed to answer the aims of this study. Thus, we were unable to examine how symptoms (e.g., anxiety and anhedonia) influence the measurement of the constructs; however, there is evidence from prior literature that measurement of neuroticism is stable even during acute depressive episodes (Costa et al., 2005) and cognitive control deficits persist after remission from depression (Porter et al., 2016; Rock et al., 2014). Other potential confounding control variables (e.g., age) were not included in the model due to sample size concerns 
but would be important to include in future studies. Finally, while we $a$ priori defined and tested potential relationships among the constructs, we then conducted additional exploratory analyses by testing alternative relationships among the constructs based on our initial results.

In summary, we found that the most parsimonious model explaining anxiety and anhedonia symptoms in patients with either early onset or either chronic or recurrent MDD consisted of pathways involving neuroticism and cognitive control. Neuroticism was positively associated with both anxiety and anhedonia, indicating a commonality underlying both symptom presentations. Lower levels of anxiety were associated with greater cognitive control, suggesting the potential importance of cognitive control as a protective mechanism against anxiety. Neuroticism had a stronger association with anxiety and anhedonia, compared to the contributions of cognitive control and reward learning. These findings contribute to the understanding of clinical symptoms and their relationship to psychological constructs, and if longitudinal studies establish the directionality of our proposed model, may also suggest possible targets for intervention that may lead to symptom improvement.

\section{Conclusion}

Individuals with MDD have heterogeneous clinical presentations, in which high levels of anxiety and anhedonia are prevalent and impairing. In a large sample of outpatients with early onset and either chronic or recurrent MDD, cross-sectional analyses found neuroticism was significantly associated with higher anxiety and anhedonia, and cognitive control was significantly associated with lower anxiety. The best fitting model did not suggest an interactive effect between neuroticism and cognitive control, or a significant effect of reward learning. Findings suggest that reducing neuroticism and improving cognitive control may be important to explore in the treatment of MDD.

\section{Author contributions}

All authors contributed to the original content and design for this paper.

Data Acquisition, analysis, and interpretation - AL, CC, CW, DD, DP, RW, MHT

Manuscript drafting: AL, RW

\section{Financial support}

The EMBARC study was supported by the National Institute of Mental Health of the National Institutes of Health under award numbers U01MH092221 (Trivedi, M.H.) and U01MH092250 (McGrath, P.J., Parsey, R.V., Weissman, M.M.). The content is solely the responsibility of the authors and does not necessarily represent the official views of the National Institutes of Health. This work was supported by the EMBARC National Coordinating Center at UT Southwestern Medical Center, Madhukar H. Trivedi, M.D., Coordinating PI, and the Data Center at Columbia and Stony Brook Universities.

\section{Conflicts of interest}

Dr. McInnis has in the past 36 months MG McInnis consulted with Janssen Pharmaceuticals and Otsuka Pharmaceuticals. Dr. Pizzagalli has over the last 36 months received consulting fees from Akili Interactive Labs, BlackThorn Therapeutics, Boehringer Ingelheim, Pfizer, and Posit Science for activities unrelated to the current research. Dr. Fava has received research support from Abbott Laboratories, Acadia Pharmaceuticals, Alkermes, Inc., American Cyanamid, Aspect Medical Systems, AstraZeneca; Avanir Pharmaceuticals, AXSOME Therapeutics, BioResearch, BrainCells Inc., Bristol-Myers Squibb, CeNeRx BioPharma, Cephalon, Cerecor, Clintara, LLC, Covance, Covidien, Eli Lilly and Company, EnVivo Pharmaceuticals, Inc.,
Euthymics Bioscience, Inc., Forest Pharmaceuticals, Inc., FORUM Pharmaceuticals, Ganeden Biotech, Inc., GlaxoSmithKline, Harvard Clinical Research Institute, Hoffman-LaRoche, Icon Clinical Research, i3 Innovus/Ingenix, Janssen R\&D, LLC, Jed Foundation, Johnson \& Johnson Pharmaceutical Research \& Development, Lichtwer Pharma $\mathrm{GmbH}$, Lorex Pharmaceuticals, Lundbeck Inc., Marinus Pharmaceuticals, MedAvante, Methylation Sciences Inc, National Alliance for Research on Schizophrenia \& Depression (NARSAD), National Center for Complementary and Alternative Medicine (NCCAM), National Coordinating Center for Integrated Medicine (NiiCM), National Institute of Drug Abuse (NIDA), National Institute of Mental Health (NIMH), Neuralstem, Inc., NeuroRx, Novartis AG, Organon Pharmaceuticals, Otsuka Pharmaceutical Development, Inc., PamLab, LLC., Pfizer Inc., Pharmacia-Upjohn, Pharmaceutical Research Associates., Inc., Pharmavite ${ }^{\circledast}$ LLC, PharmoRx Therapeutics, Photothera, Reckitt Benckiser, Roche Pharmaceuticals, RCT Logic, LLC (formerly Clinical Trials Solutions, LLC), Sanofi-Aventis US LLC, Shire, Solvay Pharmaceuticals, Inc., Stanley Medical Research Institute (SMRI), Synthelabo, Taisho Pharmaceuticals, Takeda Pharmaceuticals, Tal Medical, VistaGen, Wyeth-Ayerst Laboratories. He has also served as advisor or consultant to Abbott Laboratories, Acadia, Affectis Pharmaceuticals AG, Alkermes, Inc., Amarin Pharma Inc., Aspect Medical Systems, AstraZeneca, Auspex Pharmaceuticals, Avanir Pharmaceuticals, AXSOME Therapeutics, Bayer AG, Best Practice Project Management, Inc., Biogen, BioMarin Pharmaceuticals, Inc., Biovail Corporation, BrainCells Inc, Bristol-Myers Squibb, CeNeRx BioPharma, Cephalon, Inc., Cerecor, CNS Response, Inc., Compellis Pharmaceuticals, Cypress Pharmaceutical, Inc., DiagnoSearch Life Sciences (P) Ltd., Dinippon Sumitomo Pharma Co. Inc., Dov Pharmaceuticals, Inc., Edgemont Pharmaceuticals, Inc., Eisai Inc., Eli Lilly and Company, EnVivo Pharmaceuticals, Inc., ePharmaSolutions, EPIX Pharmaceuticals, Inc., Euthymics Bioscience, Inc., Fabre-Kramer Pharmaceuticals, Inc., Forest Pharmaceuticals, Inc., Forum Pharmaceuticals, GenOmind, LLC, GlaxoSmithKline, Grunenthal $\mathrm{GmbH}$, Indivior, i3 Innovus/Ingenis, Intracellular, Janssen Pharmaceutica, Jazz Pharmaceuticals, Inc., Johnson \& Johnson Pharmaceutical Research \& Development, LLC, Knoll Pharmaceuticals Corp., Labopharm Inc., Lorex Pharmaceuticals, Lundbeck Inc., Marinus Pharmaceuticals, MedAvante, Inc., Merck \& Co., Inc., MSI Methylation Sciences, Inc., Naurex, Inc., Navitor Pharmaceuticals, Inc., Nestle Health Sciences, Neuralstem, Inc., Neuronetics, Inc., NextWave Pharmaceuticals, Novartis AG, Nutrition 21, Orexigen Therapeutics, Inc., Organon Pharmaceuticals, Osmotica, Otsuka Pharmaceuticals, Pamlab, LLC., Pfizer Inc., PharmaStar, Pharmavite ${ }^{\circledR}$ LLC., PharmoRx Therapeutics, Precision Human Biolaboratory; Prexa Pharmaceuticals, Inc., PPD, Purdue Pharma, Puretech Ventures, PsychoGenics, Psylin Neurosciences, Inc., RCT Logic, LLC (formerly Clinical Trials Solutions, LLC), Relmada Therapeutics, Inc., Rexahn Pharmaceuticals, Inc., Ridge Diagnostics, Inc., Roche, Sanofi-Aventis US LLC., Sepracor Inc., Servier Laboratories, Schering-Plough Corporation, Shenox Pharmaceuticals, Solvay Pharmaceuticals, Inc., Somaxon Pharmaceuticals, Inc., Somerset Pharmaceuticals, Inc., Sunovion Pharmaceuticals, Supernus Pharmaceuticals, Inc., Synthelabo, Taisho Pharmaceuticals, Takeda Pharmaceutical Company Limited, Tal Medical, Inc., Tetragenex, Teva Pharmaceuticals, TransForm Pharmaceuticals, Inc., Transcept Pharmaceuticals, Inc., Usona Institute,Inc., Vanda Pharmaceuticals, Inc., Versant Venture Management, LLC, VistaGen; He has received speaking or publishing fees from Adamed, Co, Advanced Meeting Partners, American Psychiatric Association, American Society of Clinical Psychopharmacology, AstraZeneca, Belvoir Media Group, Boehringer Ingelheim GmbH, Bristol-Myers Squibb, Cephalon, Inc., CME Institute/Physicians Postgraduate Press, Inc., Eli Lilly and Company, Forest Pharmaceuticals, Inc., GlaxoSmithKline, Imedex, LLC, MGH Psychiatry Academy/Primedia, MGH Psychiatry Academy/Reed Elsevier, Novartis AG, Organon Pharmaceuticals, Pfizer Inc., PharmaStar, United BioSource, Corp., Wyeth-Ayerst Laboratories; He 
has a patent for Sequential Parallel Comparison Design (SPCD), licensed by MGH to Pharmaceutical Product Development, LLC (PPD) (US_7840419, US_7647235, US_7983936, US_8145504, US_8145505), pharmacogenomics of Depression Treatment with Folate (US_9546401, US_9540691), and a patent application for a combination of Ketamine plus Scopolamine in Major Depressive Disorder (MDD), licensed by MGH to Biohaven. Dr. McGrath has received funding from the National Institute of Mental Health, New York State Department of Mental Hygiene, Research Foundation for Mental Hygiene (New York State), Forest Research Laboratories, Sunovion Pharmaceuticals, and Naurex Pharmaceuticals (now Allergan). In the past 36 months, Dr. Trivedi has served as a consultant or on the advisory board for Alkeremes Inc., Akili Interactive, Navitor, Otsuka America Pharmaceutical Inc., Allergan Pharmaceuticals, Brintellix Global, , Global Medical Education Inc, Health Research Associates, Lundbeck Research USA, Medscape, MSI Methylation Sciences - Pamlab Inc., One Carbon Therapeutics, Pfizer Inc, Takeda Global Research, , Avanir Pharmaceuticals, Forest Pharmaceuticals, Insys, Johnson \& Johnson Pharmaceutical Research \& Development, Lilly Research Laboratories, Medscape, Merck \& Co. Inc, Mitsubishi Pharma, Neuronetics Inc., Pamlab LLC, Ridge Diagnostics, SHIRE Development LLC, Sunovion Pharmaceuticals Inc, Takeda Global Research. He has received grants from the National Institute of Mental Health (NIMH), National Institute of Drug Abuse (NIDA), National Center for Advancing Translational Sciences (NCATS), Cancer Prevention and Research Institute of Texas (CPRIT), the PatientCentered Outcomes Research Institute (PCORI), the National Institute of Diabetes and Digestive and Kidney Diseases (NIDDK), Agency for Healthcare Research and Quality (AHRQ), Johnson \& Johnson. He has author agreements with Janssen Asia Pacific and Oxford University Press. He has received honoraria from the American Psychiatric Association. And he has received royalties from Janssen Research and Development LLC. Dr. Walker's research is funded by NIDA, and Alkermes, Inc. donated medication for a NIDA-funded study unrelated to the current manuscript. Dr. Dillon has served in the last three years as a consultant for Pfizer, Inc., for activities unrelated to the current project. In the past three years, Dr. Weissman received funding from the National Institute of Mental Health (NIMH), the National Institute on Drug Abuse (NIDA), the National Alliance for Research on Schizophrenia and Depression (NARSAD), the Sackler Foundation, and the Templeton Foundation; and receives royalties from the Oxford University Press, Perseus Press, the American Psychiatric Association Press, and MultiHealth Systems. Mr. Grannemann, and Drs. Liao, Carmody, Cooper, Bruder, Webb, Shaw, Adams, Kurian, Parsey, and Phillips have no conflicts to report.

\section{Acknowledgments}

The authors would like to thank Jeremy A. Kee, M.A., for his administrative support.

\section{Supplementary materials}

Supplementary material associated with this article can be found, in the online version, at doi:10.1016/j.jad.2018.11.072.

\section{References}

Balsamo, M., Romanelli, R., Innamorati, M., Ciccarese, G., Carlucci, L., Saggino, A., 2013. The State-Trait Anxiety Inventory: shadows and lights on its construct validity. J. Psychopathol. Behav. Assess. 35 (4), 475-486. https://doi.org/10.1007/s10862-0139354-5.

Barnes, L.L.B., Harp, D., Jung, W.S., 2002. Reliability generalization of scores on the Spielberger State-Trait Anxiety Inventory. Educ. Psychol. Meas. 62 (4), 603-618. https://doi.org/10.1177/0013164402062004005.

Barnhofer, T., Chittka, T., 2010. Cognitive reactivity mediates the relationship between neuroticism and depression. Behav. Res. Ther. 48 (4), 275-281. https://doi.org/10. 1016/j.brat.2009.12.005.

Botvinick, M., Nystrom, L.E., Fissell, K., Carter, C.S., Cohen, J.D., 1999. Conflict monitoring versus selection-for-action in anterior cingulate cortex. Nature 402, 179-181. https://doi.org/10.1038/46035.

Burnham, K.P., Anderson, D.R., Huyvaert, K.P., 2011. AIC model selection and multimodal inference in behavioral ecology: Some background, observations, and comparisons. Behav. Ecol. Sociobiol. 65, 23-35. https://doi.org/10.1007/s00265-0101029-6.

Cole, D.A., Preacher, K.J., 2014. Manifest variable path analysis: potentially serious and misleading consequences due to uncorrected measurement error. Psychol. Methods 19 (2), 300-315. https://doi.org/10.1037/a0033805.

Costa, P.T., Bagby, R.M., Herbst, J.H., McCrae, R.R., 2005. Personality self-reports are concurrently reliable and valid during acute depressive episodes. J. Affect. Disord. 89, 45-55. https://doi.org/10.1016/j.jad.2005.06.010.

De Raedt, R., Koster, E.H.W., 2010. Understanding vulnerability for depression from a cognitive neuroscience perspective: a reappraisal of attentional factors and a new conceptual framework. Cogn. Affect. Behav. Neurosci. 10 (1), 50-70. https://doi.org/ 10.3758/CABN.10.1.50

Eriksen, B., Eriksen, C., 1974. Effects of noise letters upon the identification of a target letter in a nonsearch task. Percept. Psychophys. 16 (1), 143-149. https://doi.org/10. 3758/BF03203267.

Fava, M., Rush, A.J., Alpert, J.E., Balasubramani, G.K., Wisniewski, S.R., Carmin, C.N., Trivedi, M.H., 2008. Difference in treatment outcome in outpatients with anxious versus nonanxious depression: a STAR*D report. Am. J. Psychiatry 165 (3), 342-351. https://doi.org/10.1176/appi.ajp.2007.06111868.

Goldstein, B.L., Klein, D.N., 2014. A review of selected candidate endophenotypes for depression. Clin. Psychol. Rev. 34 (5), 417-427. https://doi.org/10.1016/j.cpr.2014. 06.003.

Holmes, A.J., Bogdan, R., Pizzagalli, D.A., 2010. Serotonin transporter genotype and action monitoring dysfunction: a possible substrate underlying increased vulnerability to depression. Neuropsychopharmacology 35 (5), 1186-1197. https://doi. org $/ 10.1038 /$ npp. 2009.223.

Hooper, D., Coughlan, J., Mullen, M.R., 2008. Structural equation modelling: guidelines for determining model fit. Electron. J. Bus. Res. Methods 6 (1), 53-60.

Hsu, K.J., Beard, C., Rifkin, L., Dillon, D.G., Pizzagalli, D.A., Bjorgvinsson, T., 2015. Transdiagnostic mechanisms in depression and anxiety: the role of rumination and attentional control. J. Affect. Disord. 1 (188), 22-27. https://doi.org/10.1016/j.jad. 2015.08.008.

Hu, L., Bentler, P.M., 1999. Cutoff criteria for fit indexes in covariance structure analysis: conventional criteria versus new alternatives. Struct. Equ. Model. 6 (1), 1-55. https://doi.org/10.1080/10705519909540118.

Huys, Q.J., Pizzagalli, D.A., Bogdan, R., Dayan, P., 2013. Mapping anhedonia onto reinforcement learning: a behavioural meta-analysis. Biol. Mood Anxiety Disord. 3 (1), 12. https://doi.org/10.1186/2045-5380-3-12.

Jylhä, P., Isometsä, E., 2006. The relationship of neuroticism and extraversion to symptoms of anxiety and depression in the general population. Depress. Anxiety 23 (5), 281-289. https://doi.org/10.1002/da.20167.

Kennedy, B.L., Schwab, J.J., Morris, R.L., Beldia, G., 2001. Assessment of state and trait anxiety in subjects with anxiety and depressive disorders. Psychiatr. Q. 72 (3), 263-276. https://doi.org/10.1023/A:1010305200087.

Kertz, S.J., Belden, A.C., Tillman, R., Luby, J., 2016. Cognitive control deficits in shifting and inhibition in preschool age children are associated with increased depression and anxiety over 7.5 years of development. J. Abnorm. Child Psychol. 44 (6), 1185-1196. https://doi.org/10.1007/s10802-015-0101-0.

Kline, R.B., 2015. Principles and Practice of Structural Equation Modeling, 4th ed. The Guilford Press, New York, NY.

Koster, E.H.W., Lissnyder, E.D., Derakshan, N., Raedt, R.D., 2011. Understanding depressive rumination from a cognitive science perspective: the impaired disengagement hypothesis. Clin. Psychol. Rev. 31 (1), 138-145. https://doi.org/10.1016/j.cpr. 2010.08 .005$.

Liu, W., Chan, R.C.K., Wang, L., Huang, J., Cheung, E.F.C., Gong, Q., Gollan, J.K., 2011. Deficits in sustaining reward responses in subsyndromal and syndromal major depression. Prog. Neuropsychopharmacol. Biol. Psychiatry 35 (4), 1045-1052. https:// doi.org/10.1016/j.pnpbp.2011.02.018.

Liu, W.H., Roiser, J.P., Wang, L.Z., Zhu, Y.H., Huang, J., Neumann, D.L., Chan, R.C.K., 2016. Anhedonia is associated with blunted reward sensitivity in first-degree relatives of patients with major depression. J. Affect. Disord. 190, 640-648. https:// doi.org/10.1016/j.jad.2015.10.050.

McCrae, R.R., Costa, P.T., 2007. Brief versions of the NEO-PI-3. J. Individ. Differ. 28 (3), 116-128. https://doi.org/10.1027/1614-0001.28.3.116.

McCrae, R.R., Costa, P.T., 2010. NEO Five-Factor Inventory-3 (NEO-FFI-3). Psychological Assessment Resources, Inc., Lutz, FL.

McMakin, D.L., Olino, T.M., Porta, G., Dietz, L.J., Emslie, G., Clarke, G., Brent, D.A., 2012. Anhedonia predicts poorer recovery among youth with selective serotonin reuptake inhibitor treatment-resistant depression. J. Am. Acad. Child Adolesc. Psychiatry 51 (4), 404-411. https://doi.org/10.1016/j.jaac.2012.01.011.

Mezulis, A.H., Priess, H.A., Hyde, J.S., 2011. Rumination mediates the relationship between infant temperament and adolescent depressive symptoms. Depress. Res. Treat. https://doi.org/10.1155/2011/487873.

Muris, P., 2006. Unique and interactive effects of neuroticism and effortful control on psychopathological symptoms in non-clinical adolescents. Personal. Individ. Differ. 40 (7), 1409-1419. https://doi.org/10.1016/j.paid.2005.12.001.

Muris, P., Roelofs, J., Rassin, E., Franken, I., Mayer, B., 2005. Mediating effects of rumination and worry on the links between neuroticism, anxiety and depression. Personal. Individ. Differ. 39 (6), 1105-1111. https://doi.org/10.1016/j.paid.2005. 04.005.

Nakonezny, P.A., Carmody, T.J., Morris, D.W., Kurian, B.T., Trivedi, M.H., 2010. Psychometric evaluation of the Snaith-Hamilton Pleasure Scale (SHAPS) in adult 
outpatients with major depressive disorder. Int. Clin. Psychopharmacol. 25 (6), 328-333. https://doi.org/10.1097/YIC.0b013e32833eb5ee.

Necka, E., Lech, B., Sobczyk, N., Smieja, M., 2012. How much do we know about our own cognitive control? Self-report and performance measures of executive functions. Eur. J. Psychol. Assess. 28 (3), 240-247. https://doi.org/10.1027/1015-5759/a000147.

Oei, T.P.S., Evans, L., Crook, G.M., 1990. Utility and validity of the STAI with anxiety disorder patients. Br. J. Clin. Psychol. 29 (4), 429-432. https://doi.org/10.1111/j. 2044-8260.1990.tb00906.x.

Paulus, M.P., 2015. Cognitive control in depression and anxiety: Out of control. Curr. Opin. Behav. Sci. 1, 113-120. https://doi.org/10.1016/j.cobeha.2014.12.003.

Pizzagalli, D.A., 2014. Depression, stress, and anhedonia: toward a synthesis and integrated model. Annu. Rev. Clin. Psychol. 10, 393-423. https://doi.org/10.1146/ annurev-clinpsy-050212-185606.

Pizzagalli, D.A., Iosifescu, D., Hallett, L.A., Ratner, K.G., Fava, M., 2008. Reduced hedonic capacity in major depressive disorder: evidence from a probabilistic reward task. J. Psychiatr. Res. 43 (1), 76-87. https://doi.org/10.1016/j.jpsychires.2008.03.001.

Pizzagalli, D.A., Jahn, A.L., O'Shea, J.P., 2005. Toward an objective characterization of an anhedonic phenotype: a signal-detection approach. Biol. Psychiatry 57 (4), 319-327. https://doi.org/10.1016/j.biopsych.2004.11.026.

Porter, R.J., Bourke, C., Carter, J.D., Douglas, K.M., McIntosh, V.V.W., Jordan, J., Frampton, C.M.A., 2016. No change in neuropsychological dysfunction or emotional processing during treatment of major depression with cognitive-behaviour therapy or schema therapy. Psychol. Med. 46, 393-404. https://doi.org/10.1017/ S0033291715001907.

Prinzmetal, W., McCool, C., Park, S., 2005. Attention: Reaction time and accuracy reveal different mechanisms. J. Exp. Psychol. 134 (1), 73-92. https://doi.org/10.1037/ 0096-3445.134.1.73.

Rizvi, S.J., Pizzagalli, D.A., Sproule, B.A., Kennedy, S.H., 2016. Assessing anhedonia in depression: potentials and pitfalls. Neurosci. Biobehav. Rev. 65, 21-35. https://doi. org/10.1016/j.neubiorev.2016.03.004.

Robison, M.K., Gath, K.I., Unsworth, N., 2016. The neurotic wandering mind: an individual differences investigation of neuroticism, mind-wandering, and executive control. Q. J. Exp. Psychol. 1-15. https://doi.org/10.1080/17470218.2016.1145706.

Rock, P.L., Roiser, J.P., Riedel, W.J., Blackwell, A.D., 2014. Cognitive impairment in depression: a systematic review and meta-analysis. Psychol. Med. 44 (10), 2029-2040. https://doi.org/10.1017/S0033291713002535.

Roelofs, J., Huibers, M., Peeters, F., Arntz, A., van Os, J., 2008. Rumination and worrying as possible mediators in the relation between neuroticism and symptoms of depression and anxiety in clinically depressed individuals. Behav. Res. Ther. 46 (12), 1283-1289. https://doi.org/10.1016/j.brat.2008.10.002.

Schuurmans, J., Comijs, H.C., Beekman, A.T.F., De Beurs, E., Deeg, D.J.H., Emmelkamp, P.M.G., van Dyck, R., 2005. The outcome of anxiety disorders in older people at 6year follow-up: results from the Longitudinal Aging Study Amsterdam. Acta
Psychiatr. Scand. 111 (6), 420-428. https://doi.org/10.1111/j.1600-0447.2005 00531.x.

Segerstrom, S.C., Tsao, J.C.I., Alden, L.E., Craske, M.G., 2000. Worry and rumination: repetitive thought as a concomitant and predictor of negative mood. Cogn. Ther. Res. 24 (6), 671-688. https://doi.org/10.1023/A:1005587311498.

Snaith, R.P., Hamilton, M., Morley, S., Humayan, A., Hargreaves, D., Trigwell, P., 1995. A scale for the assessment of hedonic tone: the Snaith-Hamilton Pleasure Scale. Br. J. Psychiatry 167, 99-103. https://doi.org/10.1192/bjp.167.1.99.

Spielberger, C.D., 2010. State-Trait Anxiety Inventory. In: Weiner, I.B., Craighead, W.E. (Eds.), The Corsini Encyclopedia of Psychology, Eds.4th ed. John Wiley \& Sons, Inc, Hoboken, NJ, pp. 1698-1699. https://doi.org/10.1002/9780470479216. corpsy0943.

Stauder, A., Kovacs, M., 2003. Anxiety symptoms in allergic patients: identification and risk factors. Psychosom. Med. 65, 816-823. https://doi.org/10.1097/01.PSY. 0000088620.66211.B1.

Trivedi, M.H., McGrath, P.J., Fava, M., Parsey, R.V., Kurian, B.T., Phillips, M.L. Weissman, M.M., 2016. Establishing moderators and biosignatures of antidepressant response in clinical care (EMBARC): rationale and design. J. Psychiatr. Res. 78, 11-23. https://doi.org/10.1016/j.jpsychires.2016.03.001.

Vasey, M.W., Harbaugh, C.N., Mikolich, M., Firestone, A., Bijttebier, P., 2013. Positive affectivity and attentional control moderate the link between negative affectivity and depressed mood. Personal. Individ. Differ. 54 (7), 802-807. https://doi.org/10.1016/ j.paid.2012.12.012.

Vrieze, E., Pizzagalli, D.A., Demyttenaere, K., Hompes, T., Sienaert, P., De Boer, P., Claes, S., 2013. Reduced reward learning predicts outcome in major depressive disorder. Biol. Psychiatry 73 (7), 639-645. https://doi.org/10.1016/j.biopsych.2012.10.014.

Webb, C.A., Dillon, D.G., Pechtel, P., Goer, F.K., Murray, L., Huys, Q.J., Pizzagalli, D.A., 2016. Neural correlates of three promising endophenotypes of depression: evidence from the EMBARC study. Neuropsychopharmacology 41 (2), 454-463. https://doi. org/10.1038/npp.2015.165.

Weintraub, S., Dikmen, S.S., Heaton, R.K., Tulsky, D.S., Zelazo, P.D., Bauer, P.J., Gershon, R.C., 2013. Cognition assessment using the NIH Toolbox. Neurology 80 (11 Suppl 3), S54-S64. https://doi.org/10.1212/WNL.0b013e3182872ded.

Wetter, E.K., Hankin, B.L., 2009. Mediational pathways through which positive and negative emotionality contribute to anhedonic symptoms of depression: a prospective study of adolescents. J. Abnorm. Child Psychol. 37 (4), 507-520. https://doi.org/10. 1038/nature13314.A.

Zinbarg, R.E., Mineka, S., Bobova, L., Craske, M.G., Vrshek-schallhorn, S., Griffith, J.W., Anand, D., 2016. Testing a hierarchical model of neuroticism and its cognitive facets: latent structure and prospective prediction of first onsets of anxiety and unipolar mood disorders during 3 years in late adolescence. Clin. Psychol. Sci. 4 (5), 805-824. https://doi.org/10.1177/2167702615618162. 